This item was submitted to Loughborough's Research Repository by the author.

Items in Figshare are protected by copyright, with all rights reserved, unless otherwise indicated.

\title{
Practical responses to confidentiality dilemmas in elite sport medicine
}

PLEASE CITE THE PUBLISHED VERSION

http://dx.doi.org/10.1136/bjsports-2013-092458

\section{PUBLISHER}

() BMJ Publishing Group

\section{VERSION}

AM (Accepted Manuscript)

\section{PUBLISHER STATEMENT}

This work is made available according to the conditions of the Creative Commons Attribution-NonCommercialNoDerivatives 4.0 International (CC BY-NC-ND 4.0) licence. Full details of this licence are available at: https://creativecommons.org/licenses/by-nc-nd/4.0/

\section{LICENCE}

CC BY-NC-ND 4.0

\section{REPOSITORY RECORD}

Malcolm, Dominic, and Andrea Scott. 2019. "Practical Responses to Confidentiality Dilemmas in Elite Sport Medicine". figshare. https://hdl.handle.net/2134/18863. 
Practical Responses to Confidentiality Dilemmas in Elite Sport Medicine

\section{Dominic Malcolm and Andrea Scott}

\section{Corresponding Author}

Dominic Malcolm

School of Sport, Exercise and Health Sciences, Loughborough University, Loughborough

Leicestershire LE11 3TU

Email: d.e.malcolm@lboro.ac.uk

Telephone: 44 (0)1509 226337

Fax: 44 (0)1509 226301

\section{Co-Author}

Andrea Scott

Department of Sport Development and Management

University of Chichester

Chichester, West Sussex

UK

\section{Keywords}

Confidentiality, Ethics, clinical practice, sports medicine, sports physiotherapy

Word Count 2949 


\section{Practical Responses to Confidentiality Dilemmas in Elite Sport Medicine}

Aim: To examine the ethical challenges of upholding patient confidentiality in sports medicine and the practical responses of clinicians to these challenges.

Method: Questionnaire survey and follow up semi-structured interviews with members of the British Olympic Association's Medical Committee and Physiotherapy Forum.

Results: Clinicians identified three contextual factors which influenced issues related to patient confidentiality in sports medicine: the use of confidentiality waivers; the facilities available for treatment; and the cultural norms of elite sport. They further identified interpersonal strategies used to lessen or eradicate conflicts, including emphasising the benefits and avoidance of dis-benefits for athletes, and the potential negative consequences for others.

Conclusions: Aspects of clinicians' practice environment should be designed to enable compliance with the highest levels of ethical conduct. Professional associations should establish guidelines for clinicians' interpersonal conduct in dealing with confidentiality issues and consider their provision of ethics-based CPD. They should also petition for the establishment of athletes' codes of conduct which identify a context-relevant understanding of 'serious harm' and how that might impact on information disclosure. 
The ethical challenges of practicing sports medicine are pronounced. 'Bloodgate' exemplified this and brought these challenges to public view. In the ensuing debate ethicists called for greater critical reflection on the professional norms of sports medicine, ${ }^{1}$ while a group of clinicians argued that focus on an isolated and extreme case showed 'little appreciation of the conduct of practitioners in this field, who have evolved into highly experienced and skilled specialists'. ${ }^{2}$ This paper critically reflects upon the conduct of leading clinicians as they respond to the challenges of maintaining patient confidentiality in sports medicine.

Despite recent events, appreciation of sports medicine ethics has developed considerably in recent years. Initially there was a preponderance of personal reflections. $^{3-5}$ Subsequently the factors contributing to sports medicine's ethical specificity were highlighted. These include media demands for information, ${ }^{6}$ public accessibility of medical information about athletes, ${ }^{7}$ and the demands of anti-doping policies. ${ }^{8}$ Some have presented recommendations to guide ethical practice, advocating the principles of patient autonomy, beneficence, non-maleficence and justice. ${ }^{9}$ Guidelines have been proposed for managing conflicts of interest, confidentiality and disclosure which are underpinned by the primacy of the clinician's responsibility towards the athlete-patient. ${ }^{10}$ In July 2010 the UK's Faculty of Sport and Exercise Medicine (FSEM) published its first 'Professional Code'.11

But it remains the case that there are few empirical studies of practitioner conduct. The first, published in 2002, focussed on professional football in England. ${ }^{12}$ This study concluded that evidence of poor ethical standards required that professional guidelines be implemented more effectively in future. Subsequently Anderson conducted questionnaire and interview research with sports medicine clinicians in New 
Zealand. Questionnaire data identified confidentiality, return to play decisions, conflicts of interests, and relations with team members as the ethical issues of most concern to sports doctors. ${ }^{13}$ Interview data identified contractual obligations, ${ }^{14}$ pressures generated by money, media and performance, and practitioners' multiple obligations as the factors primarily responsible for exacerbating ethical concerns. ${ }^{15}$ Dunn et al. termed these multiple obligations the doctor-patient-team triad. ${ }^{16}$ Empirical studies highlight variations in ethical perception and practice both within and between sports, and across national contexts.

This paper responds to the call for additional research into the ethical dimensions of sports clinicians' practice.12 It focusses on patient confidentiality. It advances our understanding of the ethical challenges posed by practicing in sport and highlights the ways in which healthcare professionals conduct themselves when confronted with confidentiality issues. In focussing on the strategies employed by some of the UK's most highly qualified and experienced members of the profession, the aim is to understand everyday behaviour and stimulate further reflection.

\section{METHOD}

Data were generated between January and July 2008 as part of a broader study examining the professionalisation of sports medicine in the UK. The research sample consisted of members of the British Olympic Association's (BOA) Medical Committee and Physiotherapy Forum. Both the committee and forum consist of one representative nominated by each of the 35 Olympic sport national governing bodies (NGBs). It was 
hypothesised that this sample would provide clinicians at the forefront of their respective professions in the UK.

After gaining ethical approval at the researchers' employing institution, a two phase research method was employed. First, questionnaires were used to ascertain the methods of appointment, qualifications, experience and work routines of the respective groups. A draft questionnaire was piloted with doctors and physiotherapists based at the Olympic Medical Institute. The final questionnaire consisted of 23 closed and 4 open-ended questions. Doctor questionnaires were postally distributed by the Chair of the Medical Committee and physiotherapist questionnaires were sent from the researcher's email account to 34 contacts provided by the Chair of the Physiotherapy Forum. Twenty-one doctors and 20 physiotherapists returned questionnaires directly to the researchers. This constituted response rates of $60 \%$ and $58.8 \%$ respectively (though as some respondents reported representing multiple NGBs on the respective committees, the real response rates may be higher). The response rate is line with or exceeds that gained in previous studies of this type.

The questionnaire invited respondents to participate in the second, interview phase of research. Attempts were made to interview 34 individuals who provided contact details. Ultimately interviews were conducted with 14 doctors and 14 physiotherapists, making this the largest interview sample of sports practitioners assembled in a qualitative research project on sports medicine ethics.

Interviews were semi-structured. They explored various themes on the practice and development of sports medicine and sports physiotherapy including inter- and intra- professional relations and clinician-patient interaction. All interviews were transcribed in full. Data were analysed using thematic coding. Emergent themes were 
identified according to their frequency. Data were subsequently extracted from the interview transcripts and collated to enable cross-participant comparison. Quotations were selected for inclusion in the paper if they were deemed to provide representative and clear illustrations of key themes. Respondents' gender and sport affiliations are not reported to preserve anonymity.

\section{RESULTS}

Questionnaire data indicated that the clinicians were relatively highly qualified. $45 \%$ of physiotherapists had completed, and a further $25 \%$ were currently studying for, a postgraduate degree. $76.2 \%$ of doctors had a postgraduate sports medicine qualification. Doctors participated in an average (mean) of 5.4 Continuous Professional Development (CPD) courses per year and physiotherapists an average of nine. One physiotherapist (5\%) and six doctors (28.6\%) reported attending NGB training events on medical ethics. Therefore the sample was more highly qualified than any cohort of UK sports clinicians previously studied. ${ }^{17,18} \mathrm{We}$ take this to indicate that they are representative of the elite of their respective professions.

Interviewees consistently identified the privileged nature of information exchanged in the patient-practitioner relationship. Confidentiality was described as 'absolute' and 'a strict duty' (doctors). A physiotherapist typically said, 'The most important thing is that what an athlete tells you ... is confidential and so if they don't want you to tell the coach you cannot go and tell the coach'. But interviewees also identified scenarios in which ethical issues related to maintaining confidentiality posed 
greater challenges and thus encouraged more innovative practice. These factors were contextual and interpersonal.

\section{Contextual Factors}

While no respondent spoke of contractual clauses requiring the sharing of medical information, the use of 'consent forms/waivers' or 'confidentiality systems' was reported. These permitted healthcare professionals to share information within multidisciplinary teams consisting of other clinicians and coaching, management and support staff. Participation was voluntary and athletes could withdraw at any time. However because clinicians (and coaches) expected and encouraged athletes to participate in these systems, and because the 'opt-out' had to be an explicit choice, withdrawal was rare. Clinicians reported that athletes seldom if ever objected to signing these agreements.

The physical environment of competitive sport means that injuries frequently occur, and are treated, in full public view. However the facilities available in sport (particularly to physiotherapists) often reproduce the public nature of treatment across clinical practice. As one physiotherapist noted, 'we work in an open environment so we don't have curtains, we can see what people are doing all of the time'. Interviewees noted that athletes could request to be treated in private. However, the 'opt out' basis of private consultations, and the potential disruption to the treatment of others it caused, meant they were the exception rather than the norm.

The cultural norms of the environment mirrored the openness of the physical environment. Interviewees noted that athletes who are continually subjected to testing 
and screening come to see the sharing of physiological and personal information as normal. Interviewees reported that athletes were 'more than happy' to have injuries open to wider discussion, e.g. in selection meetings. Others said that athletes rarely if ever objected to proposals to share medical information with coaching staff. For instance, one physiotherapist noted that,

It is almost assumed that anything that is said in that [treatment] room can be told back to the coach in terms of their injury. I can tell the coach what it is, how we are going to go about treating it and how long we expect them to be out.

Athletes' indifference to disclosure often stemmed from commitments to performance goals. According to one doctor, 'if it's a sports injury they don't mind [information being shared] because they want to get it fixed'.

\section{Interpersonal Factors}

Both physiotherapists and doctors revealed ways in which they tried to minimize the pressures arising from their multiple obligations by persuading athletes to share, or allow clinicians to disclose, privileged medical information. They noted that this could be more effectively done when other clinical colleagues were co-opted. One physiotherapist stated that, 'It's usually a talk between me and the athlete first of all and then we will go to the doctor and tell them what we have discussed and ask him/her what s/he thinks'. These strategies were epitomised by another physiotherapist who noted that, 'everything can be a discussion and certainly my frame of reference will always be to discuss with the athlete the importance of sharing information'. 
Discussions took various forms. Most frequently clinicians alerted athletes to the potential consequences of withholding information. Doctors and physiotherapists reported persuading athletes that sharing information was fundamentally in their own interest. For instance, they might suggest to athletes that coaches would be more sympathetic to a decline in performance if a medical cause could be identified. According to one physiotherapist,

you do what you can to convince the athlete that it would be better off for him/her, for you and for everybody if they could have this conversation with the coach and you say to the athlete 'tell the coach'. You don't tell them, the athlete does.

Secondly interpersonal discussions could focus on the increased pressure the athlete would experience if medical information remained confidential. Interviewees might tell an injured athlete that if silenced by their duty to uphold patient confidentiality the clinician would become bypassed and the athlete increasingly exposed. Another said that invoking patient confidentiality enabled the clinician to extract themselves from the doctor-athlete-team triad and therefore it becomes a problem between the two of them. They then have to sort it out'. (doctor)

Thirdly discussions could focus on the implications for others in the sporting network. For instance, one option was to suggest to athletes that all performancerelated concerns were a priori the domain of the coach who therefore had a right to be informed. Athletes could also be made aware of pressures that confidentiality requirements created for clinicians. For example, 
... the odd couple of times when somebody has said 'no I don't want you to tell the coach' ... I have said 'look lets the three of us sit down around a table so you know what I'm saying to the coach, you know what the coach is saying to me and there is no Chinese whispers going on and we can discuss the best plan and the best way forward'. That has always worked. (Physiotherapist)

Finally, the athlete's rationale for not facilitating communication could be challenged. One physiotherapist said that 'You do all those psychological tricks that one gets taught or doesn't get taught'.

\section{DISCUSSION}

Interview data illustrate the contextual and interpersonal factors which affect the way clinicians deal with the specific challenges posed by upholding patient confidentiality in sports medicine. Interviewees represented specialists and elite practitioners and identified the techniques and strategies developed to 'manage' the ethical pressures stemming from the performance demands of elite sport and clinicians' multiple obligations. This research advances previous empirical studies by detailing the practical, everyday responses of sports medicine clinicians. However, in evaluating these findings we also need to examine how the conduct of clinicians compares with existing professional codes and ethicists' recommendations for 'individuals striving for the highest levels of professional conduct in sports medicine'.10

It is clear that the contextual factors identified constrain clinicians from conforming to recommendations for best practice. As Holm et al. state, ${ }^{10}$ and the BOA's position statement on athlete confidentiality implies, ${ }^{19}$ consent should be specific, not 
reliant on open-ended or general permission, and the exception not the norm. Thus the confidentiality management systems described by interviewees restrict professionals from practicing the highest ethical standards. Most interviewees highlighted the efficacy of such arrangements, but some also recognised them as legally redundant or 'probably not worth the paper that it's written on' (doctor). The requirement on athletes to 'opt out' effectively alerts others to the health abnormality that the athlete is seeking to keep confidential and thus is clearly contrary to their interests. We echo the concerns previously raised that such practices may contain elements of coercion. ${ }^{12}$

It is also clear that the physical environment in which sports medicine is practiced hampers clinicians' ability to preserve patient confidentiality. Where treatment rooms are open access and designed for multiple simultaneous consultations/treatments, clinicians will always be compromised in meeting the ethical expectations of their profession. Allowing athletes to request a private consultation is alone insufficient because, like withdrawal from consent agreements, the request may communicate to others the presence of health concerns. We therefore suggest that environmental issues are subject to the recommendations of Section 6.2 of the FSEM Professional Code which identifies a practitioner's duty to raise concerns about facilities which compromise patient's well-being. ${ }^{11}$

The implications of practitioners' interpersonal strategies are more complex. Some of the strategies described accord with existing recommendations. Suggesting that the disclosure of information would be beneficial to the athlete conforms to the principle of beneficence and the primacy of patient interests. The short and long term health of an athlete can best be promoted, secured and maintained, ${ }^{10}$ if those who make key decisions about training and competition schedules are fully aware of the athlete's 
physical condition. Similarly efforts to alert athletes to the potentially negative impacts of non-disclosure could be justified as actions motivated by the desire to protect the athlete through minimising conflicts of interest. But Section 3.2 of the FSEM Professional Code specifically identifies that decisions about a patient's fitness should be on 'clinical grounds' and promote the 'best medical interests' of the patient (emphasis added), rather than their social or sporting interests. ${ }^{11}$ Moreover, some of the strategies reported undermine patient autonomy. For instance, discussions which entail 'psychological tricks', evoke coaches' 'right to know', or expose athletes to different or greater social pressure, bias athletes and are therefore counter to the principles of informed patient consent.

The complexity of such interpersonal strategies stems from the recognition that the requirements of sports medicine may exceed those of 'standard' medicine. ${ }^{20} \mathrm{~A}$ key case in point is the balance between welfare and harm in elite sport. A disclosure of confidential health information may be ethically justified in cases where withholding information is thought to cause serious harm to the patient or third party (e.g. because of infectious disease).11 Thus, one interviewee invoked the hypothetical scenario of a bobsleigh driver with impaired vision and argued that the potential harm (to self and others) would be serious enough to warrant disclosure. Another discussed a real-life case in which upholding a patient's right to confidentiality had potentially deprived a team of winning a tournament medal. The interviewee questioned whether the harm caused by non-disclosure was 'serious', illustrating how the structure of elite sport means that the harm that may be caused to third parties can be 'serious' in both nonhealth-related terms and in the breadth or scale of its impact: e.g., denying a teammate of a medal winning opportunity, or a nation of a victory celebration and tangible return 
for its financial investment. The consequences of essentially selfish individual acts are not different in kind from their consequences in other walks of life, but may be different in degree. While it is not ethical to break confidentiality in order to fulfil the desires/goals of a third party, it is clear that upholding patient confidentiality in elite sport may not always be compatible with the principle that a notion of 'justice' should guide ethical practice in (sports) medicine. ${ }^{9}$

\section{CONCLUSION}

While medical ethics evoke universal principles they are always applied in a social context. For instance, the FSEM Code is explicitly designed to guide rather than 'supplant the personal judgment of the practitioner'.11 The balance struck between principles and contextual efficacy should result in behaviour that is socially useful to clients but also to the clinician and broader environment. For sports medicine this must include the recognition that the ramifications of non-disclosure of medical information extend abnormally widely and have tangible negative consequences for third parties. The profession must continue to build on the increasing sophisticated appreciation of ethical conduct and practice developed in recent years. It is hoped that this process is facilitated by this research.

A number of policy recommendations emerge from this analysis. First, we recommend that non-compliance with, e.g. BOA guidance, over consent forms/waivers be addressed. Second, we recommend that professional associations and NGBs consider the place of medical ethics in their CPD provision. It is contrary that physiotherapists do more CPD training on average, but less specifically related to ethics. Third, we 
recommend that professional associations campaign and/or advise clubs and NGBs to provide healthcare professionals with suitable arrangements to organise their work discretely and, in particular, the facilities to routinely conduct consultations in private. Fourth, we recommend that professional associations establish guidelines on the legitimacy and efficacy of various interpersonal discussion strategies. Finally, we recommend that organisations representing athletes solicit their members' views on what constitutes 'serious harm' in the context of elite sport and therefore when disclosure might be warranted. A code of patient conduct, generated by the patients and their representatives in a relatively dispassionate context, will not circumvent the primacy of individual patient autonomy but will objectively establish the behavioural expectations of the client group as a whole. It could then be used to alert individual athletes to the acceptability or otherwise of their own actions and thus alleviate the pressures experienced by sports clinicians.

Funding: No external funding supported this research.

Competing Interest: None declared.

\section{What are the new findings?}

- $\quad$ There are variations in the uptake of ethics-based CPD between sports physiotherapists and doctors.

- $\quad$ Contextual factors constrain clinicians in elite sport from conforming to recommendations for best ethical practice in relation to patient confidentiality. - $\quad$ Clinicians use a range of interpersonal strategies to manage the challenges they experience in relation to maintaining patient confidentiality in elite sport.

\section{How might this impact on clinical practice in the near future?}

- The working environment of elite sport clinicians might be revised to enable and enhance their conformity to ethical guidelines in relation to safeguarding patient confidentiality. 
- CPD provision might be revised to enhance the ethical standards of sports medicine and sports physiotherapy.

- Guidelines for dealing with confidentiality issues which are more appropriate to the specific client needs and context of sports medicine might be developed. 


\section{NOTES}

${ }^{1}$ Holm S, McNamee M. Ethics in sports medicine. Brit Med J 2009;339:b3898.

2 Peirce NS, Till SH, Wotherspoon MG, et al. Authors wide of the mark. Brit Med J Rapid Response, 15 December

2009.http://www.bmj.com/content/339/bmj.b3898?tab=responses

${ }^{3}$ Crane J. Association football: the team doctor. In: Payne SDW, ed. Medicine, sport and the law. Oxford: Blackwell Scientific Publications, 1990:331-7.

${ }^{4}$ Kennedy K.W. The team doctor in rugby union football. In: Payne SDW, ed. Medicine, sport and the law. Oxford: Blackwell Scientific Publications, 1990:315-323.

${ }^{5}$ Mellion M, Walsh W. The team physician. In: Mellion MB, ed. Sports medicine secrets. Philadelphia: Hanley \& Belfus, 1994:1-4.

${ }^{6}$ Ribbans B, Ribbans H, Nightingale C, et al. Sports medicine, confidentiality and the press. Br J Sports Med 2013;47:40-3.

${ }^{7}$ Orchard J. Who owns the information? Br J Sports Med 2002;36:16-18.

8 McNamee M, Phillips N. Confidentiality, disclosure and doping in sports medicine. $\mathrm{Br} \mathrm{J}$ Sports Med 2011;45:174-77.

${ }^{9}$ Devitt BM, McCarthy C. 'I am in blood Stepp'd in so far ...': ethical dilemmas and the sports team doctor. Br J Sports Med 2010;44:175-78.

${ }^{10}$ Holm S, McNamee M, Pigozzi F. Ethical practice and sports physician protection: a proposal. Br J Sports Med 2011;45:1170-3.

${ }^{11}$ Faculty of Sport and Exercise Medicine. Professional Code. Edinburgh: FSEM.

12 Wadddington I, Roderick M. Management of medical confidentiality in English professional football clubs: some ethical problems and issues. Br J Sports Med 2002;36:118-23.

13 Anderson L, Gerrard DF. Ethical issues concerning New Zealand sports doctors. J Med Ethics 2005;31:88-92.

${ }^{14}$ Anderson L. Contractual obligations and the sharing of confidential health information in sport. J Med Ethics 2008;34:e6.

15 Anderson L. Writing a new code of ethics for sports physicians: principles and challenges. Br J Sports Med 2009;43:1079-82.

16 Dunn SR, George MS, Churchill L, et al. Ethics in sports medicine. Am J Sports Med 2007;35:840-4.

17 Waddington I, Roderick M, Naik R. Methods of appointment and qualifications of club doctors and physiotherapists in English professional football: some problems and issues. Br J Sports Med 2001;35;48-53.

18 Malcolm D. Sports medicine: a very peculiar practice? Doctors and physiotherapists in elite English rugby union. In Loland S, Skirstad B, Waddington I. eds Pain and injury in sport: social and ethical analysis. London: Routledge, 2006:165-181.

19 British Olympic Association. The British Olympic Association's position statement on athlete confidentiality. Br J Sports Med 2000;34:71-2. 
${ }^{20}$ Giordano S. A new professional code in sports medicine. Brit Med J 2010;341:c4931. 